\title{
P Wave Dispersion in COVID-19
}

\author{
Mustafa Tuncer ${ }^{1}$, Fatih Öztürk ${ }^{1 *}$, Rabia Çoldur ${ }^{1}$, Medeni Karaduman $^{1}$, Yılmaz Güneş ${ }^{2}$ \\ ${ }^{1}$ Department of Cardiology, Van Yuzuncu Yul Universty, Van, Turkey \\ ${ }^{2}$ Department of Cardiology, Bolu Abant Izzet Baysal, Bolu, Turkey
}

\begin{abstract}
The effects of COVID-19 on the heart are still not fully known. In this study, we investigated how COVID-19 affects the P interval. Electrocardiographies (ECG) of 30 COVID-19 patients and the control group consisting of 23 healthy volunteers were examined and dispersion $(\mathrm{Pd})$ of the $\mathrm{P}$ wave was calculated.

Compared to control group mean $\mathrm{Pd}(40,1 \pm 6,6$ vs. 49,6 $\pm 11,5, \mathrm{p}=0,006)$ values were significantly higher in Covid 19 patients.

Increased Pd was observed as an indication that COVID-19 affects the atriums.

Keywords: COVID-19, P Wave Dispersion, ECG, atrial fibrillation
\end{abstract}

\section{Introduction}

Coronavirus disease 2019 (COVID-19) was declared as a pandemia by the World Health Organisation on the $11^{\text {th }}$ of March, 2020. The clinical spectrum of COVID-19 varies from pneumonia to severe Acute Respiratory Syndrome (ARDS) and it can end up with death (1). Cardiac involvement of COVID-19 is identified as heart failure, myocarditis and arrhythmia $(2,3)$. In the literature, there are already studies on ventricular rhythm disorders and in these studies, QT interval and the effects of drugs on QT duration are examined $(4,5)$. Studies are also needed on how this virus, which affects the heart, has an effect on the atrium. The electrocardiographic (ECG) finding that states about the conduction and general structure of atrial tissue is the $\mathrm{P}$ wave (6, 7). The difference between the widest and narrowest $P$ waves in ECG is defined as $P$ wave dispersion (Pd) (8). Prolonged Pd is found to be associated with impaired atrial conduction and this situation is shown to be an independent risk factor for atrial fibrillation(AF) (9). In this study, we tried to determine how COVID-19 affects the P interval.

\section{Material and Method}

During April and May 2020, 30 COVID-19 patients applied to our hospital and control group with 23 healthy volunteers were enrolled. The study was approved by Van Yüzüncü Y1l University Ethics Committee.

The inclusion criteria was defined as having positive Polymerase Chain Reaction (PCR) test of COVID-19.

Patients with pregnancy, chronic kidney failure, chronic liver failure, malignancy, coronary artery disease, heart failure, heart valve disease, hypertension and diabetes mellitus were excluded from the study. Also, patients with a known rhythm disorder or a pathological ECG finding were excluded. The presence of $U$ waves in the ECG was determined as one of the exclusion criteria from the study.

12-lead ECG of participants (Nihon Kohden brand) were recorded after one hour of rest, at room temperature. For each lead three values were calculated averagely. The duration from the beginning of the $\mathrm{P}$ wave to the end were measured in all leads. Pd value was calculated by subtracting the Pmin width from the Pmax width.

Before the treatment, ECGs of all COVID-19 patients were recorded.

Echocardiography examination was conducted in all patients and the drugs taken by each patients were questioned. The Echocardiography examination was performed at least $15 \mathrm{~min}$ after the rest using a Vivid E9 (Vivid 9 Pro, General Electric Medical Systems, Milwaukee, Wisconsin, USA) device and an X5-1 transthoracic probe in the left lateral position (two-dimensional, Mmode, color Doppler echocardiography) using parasternal and apical windows. All 
Tuncer et al / Does Covid-19 affect the P wave?

Table 1. Demographic Characteristics of The Patients and The Control Group

\begin{tabular}{lccc}
\hline & $\begin{array}{c}\text { COVID-19 patients } \\
(\mathrm{n}=31)\end{array}$ & $\begin{array}{c}\text { Control group } \\
(\mathrm{n}=23)\end{array}$ & P value \\
\hline Sex (male/female) & $22 / 9$ & $15 / 8$ & 0,181 \\
Age (years) (mean \pm SD) & $43 \pm 15,6$ & $42,5 \pm 12,5$ & 0,268 \\
LVEF $(\%)($ mean $\pm S D)$ & $58,5 \pm 5,3$ & $61,60 \pm 4,7$ & 0,066 \\
LA $(\mathrm{cm})$ (mean \pm SD) & $3,79 \pm 0,34$ & $3,76 \pm 0,34$ & 0,935 \\
\hline
\end{tabular}

\#Student $\mathrm{t}$ test, Chi-square test, LVEF: left ventriculer ejection fraction, LA: left atrium, SD: Standart Deviation

Table 2. Heart Rate and Pd Values of Patients and Control Group

\begin{tabular}{lccc}
\hline & Patients $(\mathrm{n}=31)$ & Controls $(\mathrm{n}=23)$ & P value \\
\hline Heart rate $(\mathrm{bpm})($ mean $\pm \mathrm{SD})$ & $82,3 \pm 15,2$ & $79,6 \pm 12,98$ & 0,593 \\
$\mathrm{Pd}(\mathrm{msc})($ mean \pm SD) & $49,6 \pm 11,5$ & $40,1 \pm 6,6$ & 0,006 \\
\hline
\end{tabular}

\#Student t test, Pd: P wave dispersion, bpm: beats per minute

Echocardiographic examinations were performed in accordance with current guidelines and recommended standards. (10).

Statistical Analysis: Data were evaluated using SPSS version 22.0 (SPSS 16.0; SPSS Inc., Chicago, IL, USA). Normality of the variables was tested with Kolmogorov-Smirnov method. Student t test was used for the comparison of normally distributed variables and these data were expressed as mean \pm standard deviation (SD). Chi-square test was used for the comparison of categorical variables. $\mathrm{P}<0.05$ values were considered as statistically significant.

\section{Results}

The mean age of the patient group was $43 \pm 15.6$ years, the mean age of the control group was 42.5 \pm 12.5 years, and there was no statistically significant difference between the two groups $(\mathrm{p}=$ $0,268)$.

When we look at the left ventricular ejection fractions, there was no difference between the patient and control groups, respectively (58.5 \pm 5.3-61.60 $\pm 4.7 \mathrm{p}=0.066)$.

There was no difference in left atrium sizes between the patient and control groups (3.79 \pm 0.34-3.76 $\pm 0.34 \mathrm{p}=0.935)$.

Baseline demographic variables including age, sex, ejection fraction (EF), right atrium (RA) and left atrium (LA) were not significantly different between patients and control group (Table 1).

Compared to control group mean $\operatorname{Pd}(40,1 \pm 6,6$ vs. $49,6 \pm 11,5, \quad \mathrm{p}=0,006)$ values were significantly higher in Covid19 patients (Table 2).

\section{Discussion}

In our study, we found that $\mathrm{Pd}$, the arrhythmic marker of ECG, increased in COVID-19 patients. This may have important consequences in that COVID-19 may cause atrial rhythm disturbances.

The cardiovascular effects of COVID-19 was shown in many studies; heart failure, pericardial effusion, myocarditis and arrhythmias are some of these (11-13). In COVID-19, ventricular repolarization is generally emphasized in terms of arrhythmia, and there are studies that the drugs used affect the ventricular repolarization and prolong QT (14-17). Arrhythmias are complex and depend on many factors like neurohormonal, electrolytes, metabolic disorders and catecholamine imbalance $(18,19)$. The presence of all these changes in COVID-19 patients is an indication that they are sensitive to arrhythmias. These discordant changes are a trigger for rhythm disorders involving atrium, such as atrial fibrillation (AF) as well (20). AF is the cause of many thromboembolic diseases (21). In addition, atrial systolic loss in AF impairs LV volume and can reduce cardiac output by up to $25 \%$, especially in patients with diastolic dysfunction (22). Irregular and / or rapid ventricular conduction in AF can cause LV dysfunction and also tachycardia-induced cardiomyopathy in some patients $(23,24)$. Studies have shown that $\mathrm{Pd}$ increase in AF patients is a predictive indicator. In atrial conduction, $\mathrm{Pd}$ is indicative of the nonhomogeneous anisotropic distribution of myocardial fibers (25). Studies were shown $\mathrm{Pd}$ is affected by chronic diseases such as lung diseases, hypertension, hyperthyroidism and heart failure (26-29). Because of the negative effects of COVID-19 on the lung, affecting atrium is an inevitable result. In our study, the Pd value of

East J Med Volume:27, Number:1, January-March/2022 
COVID-19 patients was higher than the control group. This difference might be an evidence that COVID-19 can predispose to AF.

$\mathrm{Pd}$ value was detected to change in positive way with treatment for hypertension (27). This change may prevent the arrhythmias such as AF by improvement of Pd with treatment. One of the subjects needed to be investigated is the prevention of the AF development with the treatment that improves the impaired Pd caused by COVID-19.

One of our limitations is the relatively small sample size in our study. ECG examinations of the patients were performed, therefore we cannot evaluate the long term rhythm. Hormonal conditions affecting Pd value were not evaluated in our study, which is one of our limitations.

As a result, COVID-19 can cause atrial rhythm disorders such as AF by increasing. Thus, COVID-19 paves the way for thromboembolic events.

Conflict of interest: The authors declare that they have no conflict of interest.

Author contribution: Concept/design: F.Ö, M.T; data analysis/interpretation: M.D, R.Ç, M.T; drafting article: F.Ö, M.T; critical revision of article: F.Ö, M.T,; approval of article: F.Ö, M.T, M.D, R.Ç; statistics: F.Ö; data collection: M.T.

\section{References}

1. Kapoor A, Pandurangi U, Arora V, Gupta A, Jaswal A, Nabar A, et al. Cardiovascular risks of hydroxychloroquine in treatment and prophylaxis of COVID-19 patients: A scientific statement from the Indian Heart Rhythm Society. Indian Pacing Electrophysiol J. 2020.

2. Inciardi RM, Lupi L, Zaccone G, Italia L, Raffo $\mathrm{M}$, Tomasoni $\mathrm{D}$, et al. Cardiac involvement in a patient with coronavirus disease 2019 (COVID19). JAMA cardiology. 2020.

3. Guo T, Fan Y, Chen M. Cardiovascular implications of fatal outcomes of patients with coronavirus disease 2019 (COVID-19) JAMA Cardiol. 2020;27.

4. Mercuro NJ, Yen CF, Shim DJ, Maher TR, McCoy CM, Zimetbaum PJ, et al. Risk of QT Interval Prolongation Associated With Use of Hydroxychloroquine With or Without Concomitant Azithromycin Among Hospitalized Patients Testing Positive for Coronavirus Disease 2019 (COVID-19). JAMA cardiology. 2020.

5. Bessiere F, Roccia H, Deliniere A, Charriere R, Chevalier P, Argaud L, et al. Assessment of QT Intervals in a Case Series of Patients With Coronavirus Disease 2019 (COVID-19) Infection
Treated With Hydroxychloroquine Alone or in Combination With Azithromycin in an Intensive Care Unit. JAMA cardiology. 2020.

6. Members ATF, Camm AJ, Lip GY, De Caterina R, Savelieva I, Atar D, et al. 2012 focused update of the ESC guidelines for the management of atrial fibrillation: an update of the 2010 ESC guidelines for the management of atrial fibrillation developed with the special contribution of the European Heart Rhythm Association. European heart journal. 2012;33(21):2719-47.

7. Dilaveris PE, Gialafos JE. P-wave dispersion: A novel predictor of paroxysmal atrial fibrillation. Annals of Noninvasive Electrocardiology. 2001;6(2):159-65.

8. Perzanowski C, Ho AT, Jacobson AK. Increased P-wave dispersion predicts recurrent atrial fibrillation after cardioversion. Journal of electrocardiology. 2005;38(1):43-6.

9. Gurok MG, Korkmaz H, Yıldız S, Bakış D, Atmaca M. QT and P-wave dispersion during the manic phase of bipolar disorder. Neuropsychiatric disease and treatment. 2019;15:1805.

10. Lancellotti P, Tribouilloy C, Hagendorff A, Popescu BA, Edvardsen T, Pierard LA, et al. Recommendations for the echocardiographic assessment of native valvular regurgitation: an executive summary from the European Association of Cardiovascular Imaging. European Heart Journal-Cardiovascular Imaging. 2013;14(7):611-44.

11. Li B, Yang J, Zhao F, Zhi L, Wang X, Liu L, et al. Prevalence and impact of cardiovascular metabolic diseases on COVID-19 in China. Clinical Research in Cardiology. 2020:1-8.

12. Zheng Y, Ma Y, Zhang J, Xie X. COVID-19 and the cardiovascular system [published online ahead of print March 5, 2020]. Nat Rev Cardiol. 2020.

13. Zhou F, Yu T, Du R, Fan G, Liu Y, Liu Z, et al. Clinical course and risk factors for mortality of adult inpatients with COVID-19 in Wuhan, China: a retrospective cohort study. The lancet. 2020.

14. Dan Z, Sheng-Ming D, Qiang T. COVID-19: a recommendation to examine the effect of hydroxychloroquine in preventing infection and progression| Journal of Antimicrobial Chemotherapy. J Antimicrob Chemother. 2020:14.

Gao J, Tian Z. yang X. breakthrough: chloroquine phosphate has shown apparent efficacy in treatment of covId-19 associated pneumonia in clinical studies. biosci Trends. 2020 .

15. Chen C-Y, Wang F-L, Lin C-C. Chronic hydroxychloroquine use associated with QT prolongation and refractory ventricular arrhythmia. Clinical Toxicology. 2006;44(2):173-5.

16. Choi Y, Lim H-S, Chung D, Choi J-g, Yoon D. Risk evaluation of Azithromycin-Induced QT

East J Med Volume:27, Number:1, January-March/2022 
prolongation in real-world practice. BioMed research international. 2018;2018.

17. Li R, Wang Y, Ma Z, Ma M, Wang D, Xie G, et al. Maresin 1 mitigates inflammatory response and protects mice from sepsis. Mediators of inflammation. 2016;2016.

18. Kuipers S, Klouwenberg PMK, Cremer OL. Incidence, risk factors and outcomes of newonset atrial fibrillation in patients with sepsis: a systematic review. Critical care. 2014;18(6):688.

19. Seecheran R, Narayansingh R, Giddings S, Rampaul M, Furlonge K, Abdool K, et al. Atrial Arrhythmias in a Patient Presenting With Coronavirus Disease-2019 (COVID-19) Infection. J Investig Med High Impact Case Rep. 2020;8:2324709620925571.

20. Zimetbaum P. Atrial Fibrillation. Ann Intern Med. 2017;166(5):Itc33-itc48.

21. Deedwania PC, Lardizabal JA. Atrial fibrillation in heart failure: a comprehensive review. The American journal of medicine. 2010;123(3):198204.

22. Nerheim P, Birger-Botkin S, Piracha L, Olshansky B. Heart failure and sudden death in patients with tachycardia-induced cardiomyopathy and recurrent tachycardia. Circulation. 2004;110(3):247-52.

23. Raymond RJ, Lee AJ, Messineo FC, Manning WJ, Silverman DI. Cardiac performance early after cardioversion from atrial fibrillation. American heart journal. 1998;136(3):435-42.

24. 25. Aytemir K, ÖZER N, Atalar E, Sade E, AKSÖYEK S, ÖVÜNÇ $\mathrm{K}$, et al. $\mathrm{P}$ wave dispersion on 12-lead electrocardiography in patients with paroxysmal atrial fibrillation. Pacing and Clinical Electrophysiology. 2000;23(7):110912.

25. Guntekin U, Gunes Y, Tuncer M, Gumrukcuoglu HA, Kaya Y. The effect of altitude on P-wave and QT duration and dispersion. Pacing Clin Electrophysiol. 2008;31(7):889-92.

26. 27. Tuncer M, Gunes Y, Guntekin U, Gumrukcuoglu HA, Eryonucu B. Short-term effects of cilazapril and atenolol on P-wave dispersion in patients with hypertension. $\mathrm{Adv}$ Ther. 2008;25(2):99-105.

27. Guntekin U, Gunes Y, Simsek H, Tuncer M, Arslan S. P wave duration and dispersion in patients with hyperthyroidism and the short-term effects of antithyroid treatment. Indian Pacing Electrophysiol J. 2009;9(5):251-9.

28. Gunes Y, Tuncer M, Guntekin U, Akdag S, Gumrukcuoglu HA. Lack of diurnal variation of P-wave and QT dispersions in patients with heart failure. Pacing Clin Electrophysiol. 2008;31(8):974-8. 